\title{
Feral ungulate and macropod responses to resource scarcity and predation risk at savanna waterholes
}

\author{
Helenna Mihailou $^{1}$ (D) Dale G. Nimmo ${ }^{1}$ id $\cdot$ Melanie Massaro ${ }^{1}$ (D)
}

Received: 20 August 2021 / Revised: 11 January 2022 / Accepted: 13 January 2022 / Published online: 22 January 2022

(c) The Author(s) 2022

\begin{abstract}
When exotic species are introduced to new environments, they often have a competitive advantage over native species. In northern Australia, pigs, cattle, and water buffalo have established widespread, feral populations. As ungulates have high water requirements, they typically congregate near waterpoints. We used a fencing experiment to test whether native macropods preferentially visited savanna waterholes where large ungulates were excluded. We also investigated whether water scarcity affected the visitation behaviour and temporal activity patterns of herbivores at waterholes and whether increasing prey aggregation at waterholes increased dingo presence. We found that macropods did not use fenced waterholes preferentially over unfenced ones. Cattle presence at waterholes increased as water became scarce, while macropod and pig presence peaked in the middle of the dry season. Macropod activity declined rapidly at the end of the dry season when cattle activity was greatest, suggesting that macropods may avoid waterholes in areas utilised by cattle when competition for resources is high. Macropods and all ungulates visited waterholes more during a drought year compared to an average rainfall year. Despite increasing prey activity, dingo presence at waterholes did not increase when water became scarce. However, dingo presence increased significantly on moonless nights. Our results suggest that competition between macropods and ungulates may intensify during periods of water scarcity. Climate change and pastoral intensification are likely to increase competition for resources between ungulates and macropods in Australian savannas, potentially threatening macropod populations across the landscape in the future.
\end{abstract}

\section{Significance statement}

In northern Australia, feral populations of pigs, cattle, and water buffalo compete with native wildlife for access to water sources. As interspecific competition favours species with a size advantage, we tested whether kangaroos and wallabies (macropods) preferentially use waterholes where large ungulates (cattle and buffalo) were excluded. We found that macropods avoided waterholes when cattle presence was high but did not preferentially use waterholes where livestock were excluded. When water scarcity peaked during a drought, macropods and all three feral ungulate species visited waterholes more. However, increased prey presence at waterholes during the drought did not correspond with increased predator (dingo) presence. Our study advances the understanding of behavioural interactions between invasive and native species at important shared resources, and how this may affect wildlife conservation in an increasingly unpredictable environment.

Keywords Feral ungulate $\cdot$ Macropod $\cdot$ Savanna $\cdot$ Interspecific competition $\cdot$ Resource scarcity $\cdot$ Predation risk

\section{Introduction}

Communicated by K. Eva Ruckstuhl

Helenna Mihailou

hmihailou@csu.edu.au

1 School of Agricultural, Environmental and Veterinary Sciences, Institute for Land, Water and Society, Charles Sturt University, Albury, NSW, Australia
Niche separation minimises competitive interactions amongst sympatric species (Hasui et al. 2009; Staniewicz et al. 2018). Interspecific competition operates in two key ways: interference competition occurs when competitively dominant species directly limit the access of other species to a shared resource (e.g., aggressive interactions, food theft), while exploitative competition occurs when competitively 
dominant species indirectly limit resource access by depleting a shared resource (e.g., faster food processing) (Latham 1999; Linnell and Strand 2000). Interference competition is more likely to lead to temporal segregation of the competing species' activity because it allows inferior competitors to avoid the dominant competitor (Carothers and Jaksić 1984; Valeix et al. 2007). Interference competition can be exacerbated when competitors are forced into close contact, such as when resources are scarce and concentrated (Petren and Case 1996; Vahl et al. 2005; Valeix et al. 2007). For example, in African savannas, smaller herbivore species shift their temporal activity patterns (Valeix et al. 2007) or increase their vigilance around waterholes to minimise interactions with elephants (Loxodonta africana) (Valeix et al. 2009), which are keystone competitors in this ecosystem (Ferry 2018).

When species have a shared evolutionary history, mechanisms to reduce competition, such as differences in food selection and habitat, evolve over time (Frere et al. 2008; Beaulieu and Sockman 2012; Staniewicz et al. 2018). However, when exotic species are introduced to new environments, such mechanisms may be absent due to a lack of shared evolutionary history with native species (Goodyear 1992; Wauters et al. 2002; Baskaran et al. 2016). Predation risk and vulnerability to pathogens is often lower for exotic species in new environments (Blossey and Notzold 1995), which can provide fitness benefits and give them a competitive advantage over native species (Holway 1999; Amarasekare 2002; Brim Box et al. 2019). This may result in fitness costs for native competitors, including exclusion from preferred habitat (Ayala et al. 2007; Cheeseman et al. 2018). For example, the introduction of eastern grey squirrels (Sciurus carolinensis) to Europe caused population declines in native Eurasian red squirrels ( $S$. vulgaris) (Bertolino et al. 2014) because red squirrels were unable to change their spatial and dietary niches to avoid competition with grey squirrels (Wauters et al. 2002).

In northern Australia, several ungulate species have established feral populations since their introduction in the early 1800s (Ridpath 1991). Of those, three key species are common in Australia's tropical savanna habitats: pigs (Sus scrofa), cattle (Bos taurus, B. indicus), and Asian water buffalo (Bubalus bubalis) (Mihailou and Massaro 2021). Ungulates have high daily water requirements and congregate close to water sources, such as rivers and waterholes (Skeat et al. 1996; Tomkins and O'Reagain 2007; Graz et al. 2012). Rainfall is highly variable throughout the region (Taylor and Tulloch 1985), and the monsoonal wetdry cycle of rain affects vegetation and surface water, with water becoming scarce as the dry season progresses (see Cook and Heerdegen 2001; Kanniah et al. 2013). As water is a limiting resource in savanna habitats (Valeix et al. 2008) and interference competition favours organisms which have a size advantage (Persson 1985; Peters and Peters 1986; Nakayama and Fuiman 2010), water points may concentrate interference competition between feral ungulates and smaller native herbivores, such as macropods (family Macropodidae, including kangaroos and wallabies). As there is considerable overlap in the diets of feral ungulates and macropods in Australian savannas (Reid et al. 2020), they may also compete for food resources. Yet little is known about the competitive interactions between the two groups for access to shared resources in savanna habitats.

Along with food and water availability, predation threat is an important factor influencing macropod densities in northern Australia (Ritchie et al. 2008). As water scarcity may concentrate herbivore activity around water sources (Thrash et al. 1995), these areas can become targeted hunting grounds for predators (Valeix et al. 2010). In African savannas, increased prey aggregation at the end of the dry season causes lions (Panthera leo) to focus their hunting within $2 \mathrm{~km}$ of waterholes (Valeix et al. 2009; Valeix et al. 2010; Davidson et al. 2013). Similarly, dingoes (Canis lupus dingo)_Australia's largest terrestrial predator (excluding humans) - use waterpoints as focal hunting grounds for native macropods and feral ungulates (Shepherd 1981; Thomson 1992; Forsyth et al. 2019). Hence, herbivores become increasingly more exposed to dingo predation as the dry season progresses, because they congregate in areas near available water and must drink more frequently due to the drying of fodder (Letnic et al. 2012). Additionally, the nocturnal activity and hunting efficacy of some predatory animals increase during the full moon, when night-time illumination is greatest (e.g., Cozzi et al. 2012; Pratas-Santiago et al. 2016). By contrast, prey animals may reduce their activity when night-time illumination is high (e.g., full moon, reduced cloud cover) to decrease predation risk (e.g., Harmsen et al. 2011; Linley et al. 2020). Healthy adult cattle and buffalo are considered too large for dingoes to kill, but calves and weak adults are vulnerable to predation (Thomson 1992; Corbett 1995b; Fleming et al. 2001). Dingoes also prey on feral pigs of all ages in tropical Australia (Corbett 1995a; Fleming et al. 2001; Brook and Kutt 2011).

Exclusion fencing provides a method to identify interspecific competition and its impacts on the spatial and temporal behaviour of species (Ziv et al. 1993; Hall et al. 2016, 2018). In this study, we conducted a fencing experiment to investigate whether the exclusion of large feral ungulates (cattle and buffalo) from ephemeral savanna waterholes affected the behaviour of native macropods in northern Australia. We also assessed whether the visitation behaviour and temporal activity patterns of these species varied with increasing water scarcity and the activity of dingoes, a predator of both macropods and ungulates. We hypothesised that competition from feral ungulates leads macropods to preferentially use sites where cattle and buffalo were excluded, 
particularly when water becomes scarce (i.e., as the dry season progressed). At sites accessible to cattle and buffalo, we expected macropods to shift their temporal activity to avoid overlap with large ungulates. We also hypothesised that water scarcity increases prey visitation to waterholes, leading to increased dingo visitation. We also expected that dingo activity around waterholes increases during the full moon, while prey species decrease their activity. The reverse was expected when night-time illumination was low.

\section{Methods}

\section{Study area}

This study was conducted in Limmen National Park, a reserve which protects over a million hectares of mixed savanna woodland in the Gulf of Carpentaria region of the Northern Territory, Australia. The park has an average annual rainfall of $859 \mathrm{~mm}$ (as measured at Nathan River Ranger Station, Bureau of Meteorology 2021), which falls throughout the "wet season" ( November to March), while little to no rain is received throughout the "dry season" ( April to October) (full rainfall statistics for the site $(014,719)$ from 1979 to present are available via the Bureau of Meteorology at http://www.bom.gov.au/climate/data). Ephemeral waterholes are common within the park and are typically small clay basins, which dry completely by the end of the dry season and are refilled at the start of each wet season. Rainfall varied considerably in the region over the sampling period, with $970 \mathrm{~mm}$ and $371 \mathrm{~mm}$ falling over the 2017/2018 and 2018/2019 wet seasons respectively (Bureau of Meteorology 2021). For simplicity, hereafter we refer to the $2017 / 2018$ wet season as " 2018 " and the $2018 / 2019$ wet season as "2019."

\section{Site selection and experimental design}

All waterholes used in this study were ephemeral clay basins located in predominately clay soils with open mixed savanna woodland in the surrounding area. Rocky and sandy basin waterholes and those located at the base of ridgelines and within $1 \mathrm{~km}$ of larger watercourses (e.g., rivers, large permanent billabongs) were excluded. We selected 20 waterholes that were similar in size, depth, surrounding vegetation, and soil type (see Fig. 1 for an example). We then used a paired experimental design where we assigned the most similar waterholes into pairs based on their physical properties (as outlined above) and estimated ungulate disturbance (e.g., determined from foot pugging, dung pats, tracks, wallows). From each pair of waterholes, we then randomly selected one site as a control (unfenced) and the other as a treatment site (fenced). Distribution of study waterholes is shown in Fig. 2. All study waterholes were located within 1-2 km of an alternative water source to minimise the likelihood that fencing would affect animal visitation to unfenced study waterholes.

Fences were erected in September 2017 to prevent waterhole access by cattle and buffalo, as well as horses (Equus caballus) and donkeys (E. asinus), which occur in much lower densities in the study area and were not included in this study. Macropods, dingoes, and other native wildlife were able to move beneath fences and had continued access to fenced waterholes. We were not able to exclude pigs from fenced sites because the use of meshed, pig-proof fencing would have also hindered the access of native wildlife, including macropods and dingoes. Hence, our paired
Fig. 1 A typical savanna waterhole in Limmen National Park (left) and an example of the reinforced, four-strand wire fencing design used to exclude cattle and buffalo (right)
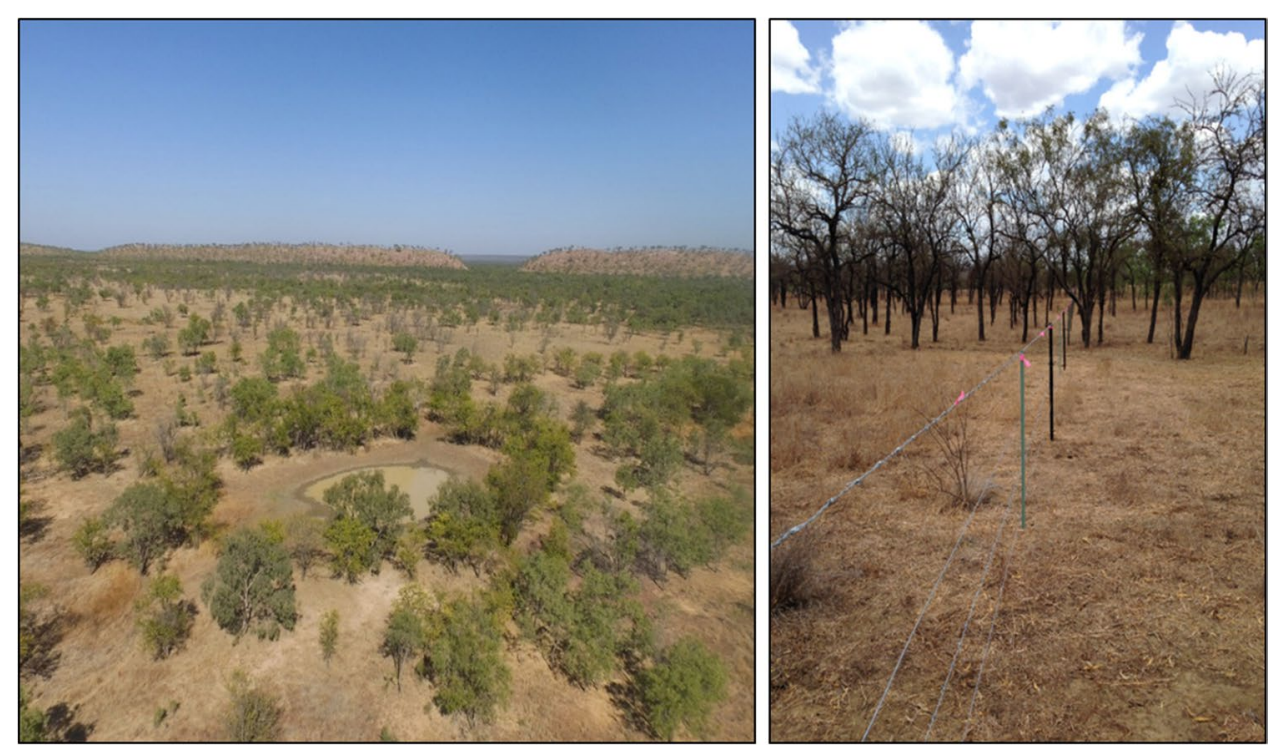
Fig. 2 Distribution of study waterholes within Limmen National Park. Red circles represent fenced sites; while yellow circles represent unfenced sites

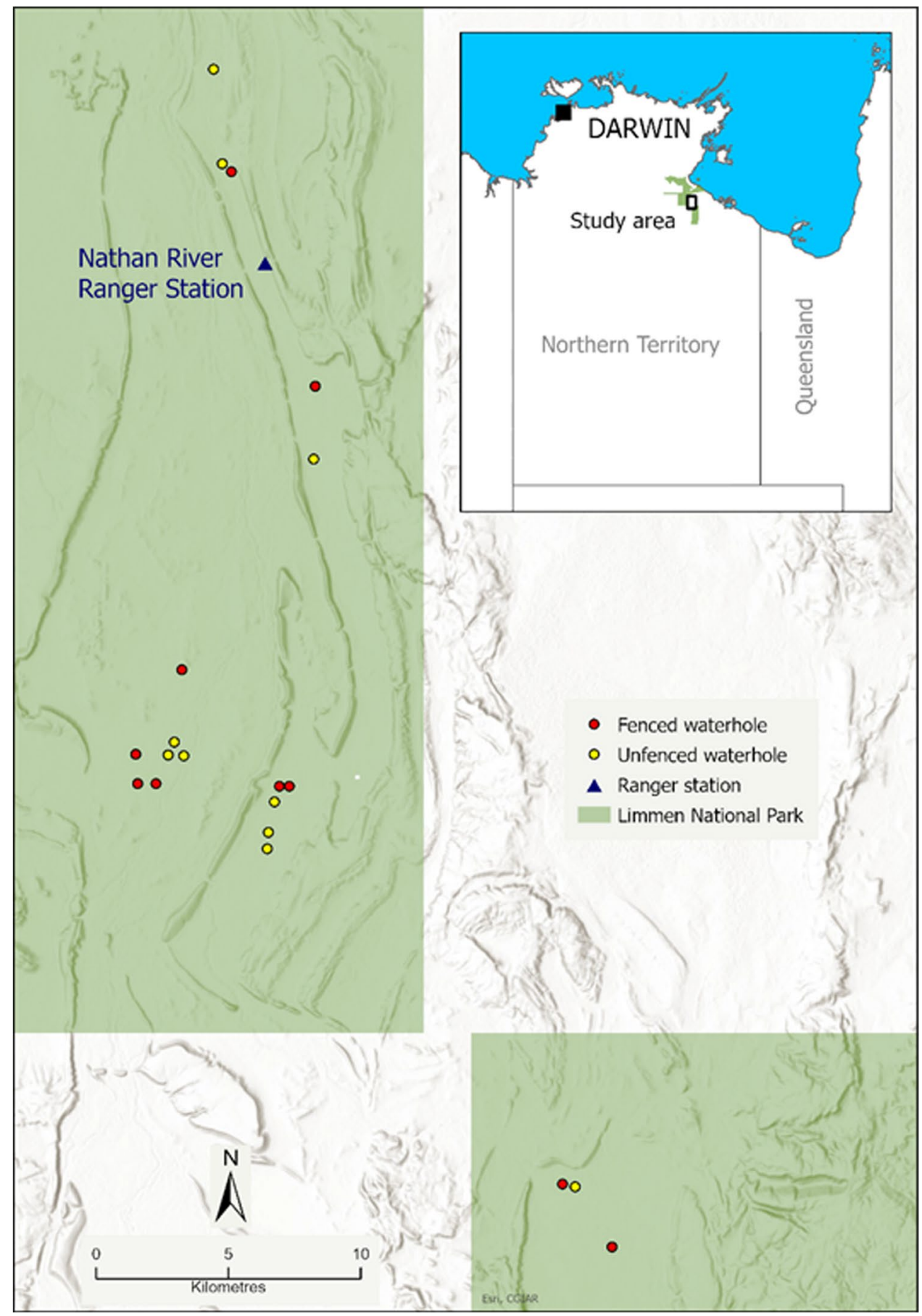

experimental design allowed us to assess if there were differences in the temporal and visitation behaviours of species which could access both fenced and unfenced sites (i.e., macropods, pigs, and dingoes).

Fences were $150 \times 150 \mathrm{~m}$ long and were positioned around treatment sites, such that the waterhole was in the centre of the fenced area. Fencing design was a standard four-strand, star picket fence, with barbed wire at approximately $120 \mathrm{~cm}$ and $60 \mathrm{~cm}$ above the ground (top and third line of fence) and galvanised plain wire in between (see Fig. 1). Fences were reinforced against ungulate damage by spacing pickets at 7-m intervals (rather than the 10 to 12-m spacing typically used) and including a steel dropper between pickets to help maintain tension under stress. Regular fence checks and maintenance were carried out at roughly 4-week intervals and fences re-strained as necessary. Fences were breached occasionally $(<1$ per month across all sites) but were always repaired prior to cameras being 
deployed. Hence, large ungulate access was restricted during all sampling.

Sites were protected from fire as much as possible over the duration of the study by using controlled, early season burns to create fire breaks around each site ( $>1 \mathrm{~km}$ away). Despite these precautions, lightning strikes in December 2018 started fires which affected 6 study sites. However, an equal number of fenced and unfenced sites were impacted.

\section{Data collection}

Field work was conducted from April to October in 2018 and March to August in 2019. Study sites were sampled on a 5-week rotation (4 waterholes per week) from the beginning of the dry season, until each waterhole dried out. The order in which sites were sampled was based on accessibility at the start of the dry season; however, once sampling order was established, it was maintained throughout each season. Paired sites were typically sampled at the same time. However, this was not always logistically possible due to poor condition of $4 \mathrm{WD}$ tracks within the park, which prolonged travelling times between some paired sites. To limit the potential for non-simultaneous sampling of some pairs to affect the fencing experiment, an approximately equal number of fenced and unfenced sites were sampled first each time.

Reconyx Hyperfire HC600 motion triggered wildlife cameras ("camera traps") were used to sample animal presence at waterholes. Camera traps were set up around each waterhole for 5 continuous day/night cycles and were set to take 3 photos at 1-s intervals when triggered by movement or body heat (key settings used; trigger: sensitive, night mode: max range, quiet period: no delay). Cameras were set up using two different sampling methods to maximise detection likelihood: 3 cameras were mounted to trees around each waterhole and positioned to capture as much of the waterline as possible, and a further 2 cameras were placed in the surrounding savanna within each study plot (i.e., $<75 \mathrm{~m}$ from water), mounted to horizontal tree branches and positioned facing directly downwards above a staked cork-tile baited with a mixture of linseed and tuna oils. Waterhole facing cameras were mounted at approximately $1.3 \mathrm{~m}$ above the ground to minimise false triggers from ground vegetation, while downward facing cameras were mounted approximately $1.8 \mathrm{~m}$ above ground (wherever possible) to standardise camera field of view. Both types of camera trapping method were used in each study plot at the same time and for the same duration within a given sample rotation (i.e., 5 day/ night cycles). Photos from waterline cameras were pooled with baited camera photos to compile presence/absence data for animals visiting each study plot (i.e., the waterhole and its immediate surrounds). This prevented double counts of animals which entered the field of view of multiple cameras during a visit to a waterhole and/or a baited cork-tile in the surrounding savanna. In total, cameras were deployed at sites across the duration of the study for 740 trap nights.

\section{Data processing}

Photos taken by cameras were examined, their meta-data collated (i.e., date and time of photo capture) and the species present identified using the database program, CPW Photo Warehouse version 4.3.0.5 (Newkirk 2016). Given the geographic location of the study area, sunrise and sunset times did not fluctuate by $>1 \mathrm{~h}$ over the data collection period and were defined as follows: sunrise ( $6 \mathrm{am}-7 \mathrm{am})$, sunset $(6 \mathrm{pm}-7 \mathrm{pm})$. It was not possible to record data blind because characteristics which identified each study waterhole were visible in photos which the observer had to process.

The response variable for our analysis was the presence or absence of a species at a site within any given hour of sampling. Hence, each time a target species was detected at a study waterhole, we recorded the hour of day the detection occurred within that 24-h period (i.e., hour 0-23). As the variable is presence/absence rather than a count of visitation events, multiple visits within a given hour still only represented a single data point. This method was then applied over the entire period cameras were deployed at each site over each season and then pooled to create a 24 -h representation of temporal activity for each species studied.

We included several predictor variables in our analysis: fencing treatment (i.e., fenced or unfenced), number of days since the dry season started (as a continuous variable), year, and moon phase. Fencing treatment was included as a fixed factor for macropod, pig, and dingo models only, because they were present in both treatments. Fencing was not included as a variable in cattle and buffalo models, because they could not access fenced sites. Although we observed waterholes for a total of $17,761 \mathrm{~h}$, the different species studied here (i.e., ungulates, macropods, and dingos) rarely visited waterholes simultaneously. There were only 81 instances in which more than one species visited the same waterhole within the same hour, and the number of instances in which specific competitors visited waterholes at the same time (e.g., macropods and cattle) is an even smaller fraction of this number. Hence, the inclusion of presence/absence of heterospecifics as covariates in our modelling was not possible, as the amount of zero inflation prevented model convergence.

Due to differences in the amount and date that rainfall fell across the 2017/2018 and 2018/2019 wet seasons, the date the dry season started differed between years. Given that researchers lived on site and could begin sampling as soon as rains ceased and tracks became accessible, the date sampling began was taken as the start of the dry season. Year 
and moon phase were also included as fixed factors. Moon phase was classified into 3 categories: waxing/waning moon, no moon, and full moon. To assess whether the activity of species changed in response to moonlight intensity, we used activity in the wax/wane phase as a baseline to compare activity during the no moon and full moon phases. The dates considered as no moon and full moon were taken as the day of the phase \pm 3 days (following Coulson 1982), and all days between were classified as waxing/waning days. Data was collected during the dry season when cloud cover is absent. Study site was included as a random effect to account for repeated sampling of sites. See Table 1 for a summary of the number of trap nights cameras sampled each variable.

All $n$ values reported are the total number of hours a given species was detected in (i.e., hours present). As we were interested in whether macropods as a family were affected by the presence of feral ungulates and dingoes around savanna waterholes, data from all macropod species detected by cameras was pooled into a single dataset.

\section{Data analyses}

Generalised additive mixed-effect models (GAMMs) were used to analyse temporal activity data. This approach was taken because this type of regression is able to model nonlinear relationships (Wood 2006), which was necessary given temporal dynamics of species over the diel cycle are often highly non-linear. Additionally, GAMMs allow the effects of multiple covariates on the response variable to be modelled at the same time (unlike pairwise comparisons). A binomial distribution with a logit link function was used because our response variable was a vector of ones and zeroes (i.e., species present $=1$, species absent $=0$ within

Table 1 The number of trap nights sampled for each variable used in analyses

\begin{tabular}{llll}
\hline \multirow{2}{*}{ Year } & & \multicolumn{2}{l}{$\begin{array}{l}\text { Number of trap nights } \\
\text { sampled }\end{array}$} \\
\cline { 3 - 4 } & & $\begin{array}{l}\text { Both fence } \\
\text { treatments }\end{array}$ & $\begin{array}{l}\text { Unfenced } \\
\text { sites } \text { only }^{\wedge}\end{array}$ \\
Moon phase & 2018 & 446 & 226 \\
& 2019 & 294 & 168 \\
Subset dry season & Wax/wane & 394 & 208 \\
& No moon & 171 & 90 \\
& Full moon & 175 & 96 \\
Total sampling effort & Start & 294 & 145 \\
& Middle & 262 & 146 \\
& End & 184 & 103 \\
& & 740 & 394 \\
\hline
\end{tabular}

*Denotes data used for macropod, pig, and dingo models

${ }^{\wedge}$ Denotes data used for cow and buffalo models a given hour of day). We used GAMMs to model the probability of presence of each species against time of day, to the nearest hour, specified as a smoothed term fitted to a cyclical cubic regression spline (Wood and Scheipl 2020). We used a cyclic spline so that there would be no discontinuity between first and last hours of the day (i.e., over the cusp of midnight), allowing us to produce curves which illustrate the temporal activity patterns for each species (see Cunningham et al. 2019).

To determine whether the temporal activity patterns of macropods, pigs, and dingoes differed between fenced and unfenced sites, fencing treatment was included as a categorical variable with two levels: fenced and unfenced. We compared the base model for each of these species with a variable co-efficient GAMM that included an interaction between treatment and time of day using the "by" function (Wood and Scheipl 2020). This allowed the generation of a separate smoothed term for fenced and unfenced sites (see Wood 2006; Zuur et al. 2009) so we could compare whether the temporal activity patterns of species differed between fencing treatments. We also determined whether the inclusion of an additional smoothed term was required to model the relationship between species presence and dry season progression, as the data indicated this relationship may have been non-linear for some species. Akaike's Information Criterion (AIC; Akaike 1973) was calculated to compare models with and without the interaction and smooth terms to determine which model was most parsimonious.

To investigate how dry season progression affected temporal activity patterns we divided the data for each species into three stages of the dry season: start, middle, and end. Sub-setting the data in this manner allowed us to create separate temporal activity curves for each species in each treatment (where possible) during each stage of the dry season. We followed the same model selection process as outlined above for the base models to determine whether the temporal activity patterns of macropods, pigs, and dingoes differed in fenced and unfenced sites at different stages of the dry season. We accounted for variation between years in the number of days sites were sampled over the dry season due to study waterholes drying out at slightly different times ( $n_{2018}=173$ days, $n_{2019}=150$ days). It is important to note that our definition of the end of the dry season is based on the drying of ephemeral waterholes in the study area, rather than the true end of the season per se (i.e., when first storms begin). See Table 1 for a summary of the number of trap nights cameras sampled each subset category of the dry season.

All models were created using the "gamm4" package (Wood and Scheipl 2020) in statistical program, R (R Core Team 2020). Figures were then generated with $R$ by using these models to calculate predicted hourly presence values using the "ggpredict" function from package "ggeffects" 
(Lüdecke 2018) and plotted with "ggplot2" (Wickham 2016).

\section{Results}

\section{General waterhole use}

Buffalo and cattle were present around waterholes approximately twice as much as the other species studied $\left(n_{\text {buffalo }}=162 \mathrm{~h}, n_{\text {cow }}=149 \mathrm{~h}\right.$; where $n$ is the number of hour-long sample blocks during which the species was detected). Dingoes were detected more often than macropods $\left(n_{\text {dingo }}=81 \mathrm{~h}, n_{\text {macropod }}=70 \mathrm{~h}\right)$, while pigs were detected least often $\left(n_{\text {pig }}=65 \mathrm{~h}\right)$. Macropod species detected on cameras included primarily northern nailtail wallaby (Onychogalea unguifera, $n=27 \mathrm{~h}$ ) and antilopine kangaroo (Macropus antilopinus, $n=18 \mathrm{~h}$ ), although agile wallabies (M. agilis, $n=3 \mathrm{~h}$ ) were also detected in very low numbers. Macropods which could not be identified to the species level were detected in a further 22 hours, although most of these were likely antilopine kangaroos based on their size.

We found that the general activity of all species (across the entire dry season) varied significantly with time of day (Table 2). Macropods were active at night, with peak activity occurring around $11 \mathrm{pm}$ (Fig. 3a). Pigs were most active in the early morning, with a peak in activity just before dawn (Fig. 3b). Cattle were active during daylight hours, with their activity rising steadily from dawn and peaking in the late afternoon before dropping quickly around dusk (Fig. 3c). Buffalo activity had two distinct peaks around dawn and dusk, but they were more active around dusk (Fig. 3d). Dingo activity was similar to that of buffalo, with two distinct peaks around dawn and dusk, but they were most active around dawn (Fig. 3e).
Table 2 GAMM results which show the influence of predictor variables on the predicted hourly presence of species visiting waterholes

\begin{tabular}{|c|c|c|c|c|c|c|}
\hline Species & & Macropod & Pig & Cow & Buffalo & Dingo \\
\hline Total $n$ & & 70 & 65 & 149 & 162 & 81 \\
\hline \multirow[t]{3}{*}{ Smoothed term (time) } & $e d f$ & 3.014 & 2.707 & 3.486 & 3.072 & 3.191 \\
\hline & Chi-sq & 37.17 & 26.74 & 52.91 & 9.521 & 15.62 \\
\hline & $p$ & $<0.001$ & $<0.001$ & $<0.001$ & 0.0173 & $<0.001$ \\
\hline \multirow[t]{4}{*}{ Fencing treatment } & $n(f, u n f)$ & 37,33 & 28,37 & - & - & 36,45 \\
\hline & St. error & 0.7764 & 0.7259 & - & - & 0.2912 \\
\hline & $z$ & -1.142 & 0.359 & - & - & 0.449 \\
\hline & $p$ & 0.2533 & 0.7197 & - & - & 0.6531 \\
\hline \multirow[t]{4}{*}{ Year } & $n(2018,2019)$ & 30,40 & 18,47 & 43,106 & 76,86 & 46,35 \\
\hline & St. error & 0.3509 & 0.2971 & 0.1903 & 0.1623 & 0.2367 \\
\hline & $z$ & 3.814 & 3.68 & 6.484 & 2.572 & 0.89 \\
\hline & $p$ & $<0.001$ & $<0.001$ & $<0.001$ & 0.0101 & 0.3735 \\
\hline \multirow{3}{*}{$\begin{array}{l}\text { Smoothed term (days since dry } \\
\text { season began) }\end{array}$} & $e d f$ & 5.286 & 4.077 & - & - & - \\
\hline & Chi-sq & 49.67 & 18.55 & - & - & - \\
\hline & $p$ & $<0.001$ & 0.00111 & - & - & - \\
\hline \multirow[t]{3}{*}{ Dry season progression (overall) } & St. error & - & - & 0.002318 & 0.001949 & 0.002586 \\
\hline & $z$ & - & - & 2.833 & -1.313 & 1.752 \\
\hline & $p$ & - & - & 0.00461 & 0.1892 & 0.0798 \\
\hline \multirow[t]{4}{*}{ No moon } & $n($ no, wax $)$ & 18,38 & 8,36 & 31,75 & 21,80 & 30,39 \\
\hline & St. error & 0.3343 & 0.4269 & 0.2246 & 0.2487 & 0.2498 \\
\hline & $z$ & 1.623 & -1.33 & 0.831 & -1.943 & 2.303 \\
\hline & $p$ & 0.1046 & 0.1836 & 0.406 & 0.05198 & 0.0213 \\
\hline \multirow[t]{4}{*}{ Full moon } & $n(f u l l$, wax $)$ & 14,38 & 21,36 & 43,75 & 61,80 & 12,39 \\
\hline & St. error & 0.3575 & 0.3023 & 0.2091 & 0.1855 & 0.3432 \\
\hline & $z$ & -1.445 & 0.014 & -0.755 & 2.775 & -1.408 \\
\hline & $p$ & 0.1484 & 0.9889 & 0.4501 & 0.00552 & 0.1591 \\
\hline $\operatorname{Adj} . r^{2}(\%)$ & & 1.02 & 0.549 & 1.53 & 0.384 & 0.161 \\
\hline
\end{tabular}

Significant $p$ values $(<0.05)$ are displayed in bold; hyphens denote variables not included in models. Total $n$ is the number of hours a species was detected in. Smoothed term describes the deviation of predicted presence from zero. For $n$ values, (f, unf) denotes (fenced, unfenced); (no, wax, full) denote moon phases 
Fig. 3 General temporal activity patterns (the predicted hourly presence) over a 24-h day of macropods (a), pigs (b), cattle (c), buffalo (d), and dingoes (e) at savanna waterholes in Limmen National Park. Lines denote mean presence values, while grey areas represent upper and lower $95 \%$ confidence intervals
A
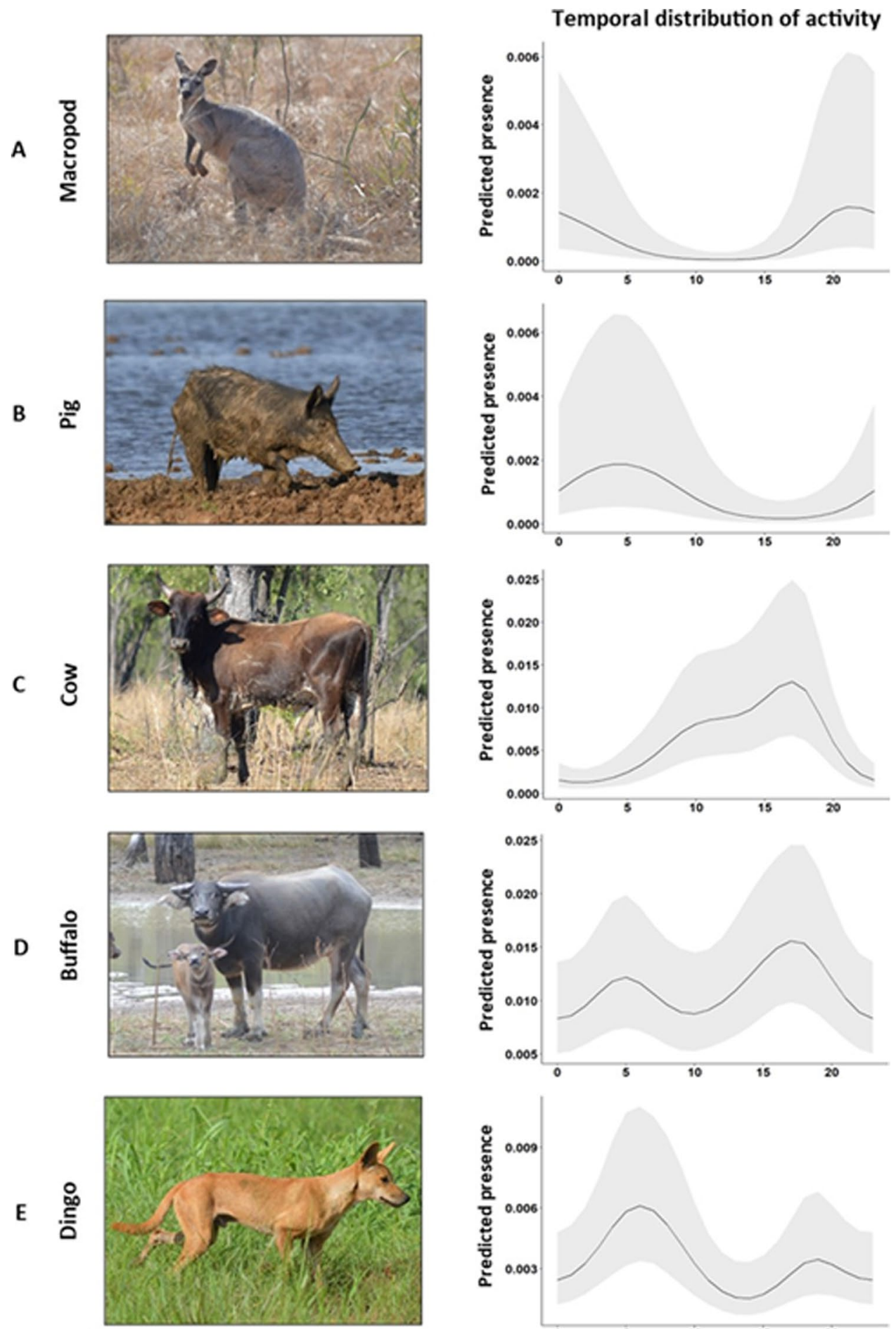

\section{Fencing treatment}

We found no significant difference in the predicted hourly presence of macropods, pigs, and dingoes in fenced and unfenced sites (Table 2). The addition of an interaction term (a by factor) between fencing treatment and time of day resulted in a less parsimonious model for all species (i.e., higher AIC, see online supplementary material Table S1), indicating that the temporal activity patterns of macropods, pigs, and dingoes did not differ substantially between fenced and unfenced sites over the entire dry season. 
When we considered the dry season as three stages, we found that macropods, pigs, and dingoes did not use fenced sites significantly more than unfenced ones (see online supplementary material Table S2). In addition, the temporal activity patterns of dingoes did not differ significantly between fencing treatments during different stages (i.e., $\Delta$ AIC for all models $\geq 2$, and model with by factor removed was the most favourable; Table S2). This was also the case for macropods and pigs during the start and end of the dry season (Table S2). However, the temporal activity of macropods and pigs did differ significantly between fencing treatments during the middle of the season when the presence of both species peaked (see Table 3 for significance of smooth results), although the model without a by factor for fencing was still the most parsimonious in both cases (Table S2). Macropod presence at fenced sites during the middle of the dry season was greater than at unfenced sites (although not significantly so-Table 4), and their temporal activity patterns (Fig. 4a) were similar to those observed overall (Fig. 3a). At unfenced sites in the middle of the dry season, macropods did not have well-defined temporal patterns (Fig. 4a), although their activity peaked at $\sim 2$ am as opposed to $\sim 9 \mathrm{pm}$ in fenced sites. This may have been due to low macropod visitation to unfenced sites during this stage $(n=9)$, which is supported by the lack of difference seen in the temporal activity patterns of macropods in different fencing treatments at the end of the dry season (when macropods visited unfenced sites more, $n=24$ ). Pig activity patterns in fenced and unfenced sites during the middle of the dry season (Fig. 4b) were more consistent with those observed overall (Fig. 3b); however, their activity at unfenced sites peaked a few hours earlier $(\sim 1 \mathrm{am})$ than at unfenced sites ( 4 am) (Fig. 4b).

\section{Water scarcity}

Overall, the predicted presence of cattle and dingoes increased in a linear pattern as the dry season progressed (cattle: Fig. 5c, dingoes: online supplementary material Fig. S2); however, this increase was only significant for cattle (Table 2). Buffalo presence declined in a linear pattern as the dry season progressed and was not significant (Fig. S2, Table 2). In contrast, macropod and pig presence had a non-linear relationship with dry season progression (Fig. 5a, b respectively). The visitation of both species increased gradually before peaking in the middle of the dry season and then declining sharply towards the end of the dry season. In 2018, there were zero macropod detections in the last 34 days of sampling, and in 2019 there were only 2 detections in the last 40 days of sampling. Pigs followed a similar pattern, with zero detections in the last 52 days of sampling in 2018, and only 3 detections in the last 40 days of sampling in 2019.

Year had a significant effect on the predicted presence of all species, except dingoes (Table 2; Fig. 6). The mean hourly presences of macropods, pigs, cattle, and buffalo were significantly higher in 2019 (drought year) than in 2018, and this response was greatest in cattle.

\section{Moon phase}

The presence of dingoes increased significantly during the no moon compared to the wax/wane phase, whereas there was no significant difference detected for macropods, pigs, cattle, and buffalo (Table 2, Fig. 7). During the full moon, buffalo presence was significantly greater than in the wax/wane phase,
Table 3 Significance of smooth results showing the presence $(p<0.05)$ or absence $(p>0.05)$ of temporal activity patterns for species during different stages of the dry season (start, middle, and end). The inclusion of fencing treatment as a by factor was only supported for macropods and pigs, and only during the middle of the dry season

\begin{tabular}{lllllllc}
\hline Dry season stage & Species & Model terms & Fencing treatment & $n$ & St. error & $z$ & $p$ \\
\hline Start & Macropod & Base model & Both & 3 & 0.4686 & 0.638 & 0.251 \\
& Pig & Base model & Both & 17 & $6.044 \mathrm{e}-06$ & 0.00 & 0.61 \\
& Dingo & Base model & Both & 22 & 3.181 & 11.08 & $\mathbf{0 . 0 0 8 9 2}$ \\
Middle & Macropod & Base model & Both & 35 & 2.691 & 20.75 & $<\mathbf{0 . 0 0 1}$ \\
& & By factor for fencing & Fenced & 26 & 2.503 & 17.78 & $<\mathbf{0 . 0 0 1}$ \\
& & treatment included & Unfenced & 9 & 1.567 & 4.741 & $\mathbf{0 . 0 3 6 7}$ \\
& Pig & Base model & Both & 24 & 2.302 & 15.71 & $<\mathbf{0 . 0 0 1}$ \\
& & By factor for fencing & Fenced & 13 & 2.09 & 11.43 & $\mathbf{0 . 0 0 1 5 1}$ \\
End & treatment included & Unfenced & 11 & 1.996 & 9.077 & $\mathbf{0 . 0 0 5 0 2}$ \\
& \multirow{4}{*}{ Dingo } & Base model & Both & 32 & 1.435 & 4.00 & $\mathbf{0 . 0 4 9 2}$ \\
& Macropod & Base model & Both & 32 & 2.667 & 19.16 & $<\mathbf{0 . 0 0 1}$ \\
& Pig & Base model & Both & 24 & 2.668 & 14.62 & $<\mathbf{0 . 0 0 1}$ \\
& Dingo & Base model & Both & 27 & $7.42 \mathrm{e}-09$ & 0.00 & 1.00 \\
\hline
\end{tabular}

Significant $p$ values $(<0.05)$ are displayed in bold and indicate that predicted presence deviated significantly from zero with time of day (i.e., there was a temporal activity pattern). Values for $n$ are the number of hours presence was detected in each stage of the dry season. See methods for a description of variables included in base models 
Fig. 4 Temporal activity patterns of macropods (a) and pigs (b) at fenced and unfenced sites in the middle of the dry season. Lines denote mean presence values, while grey areas represent upper and lower $95 \%$ confidence intervals
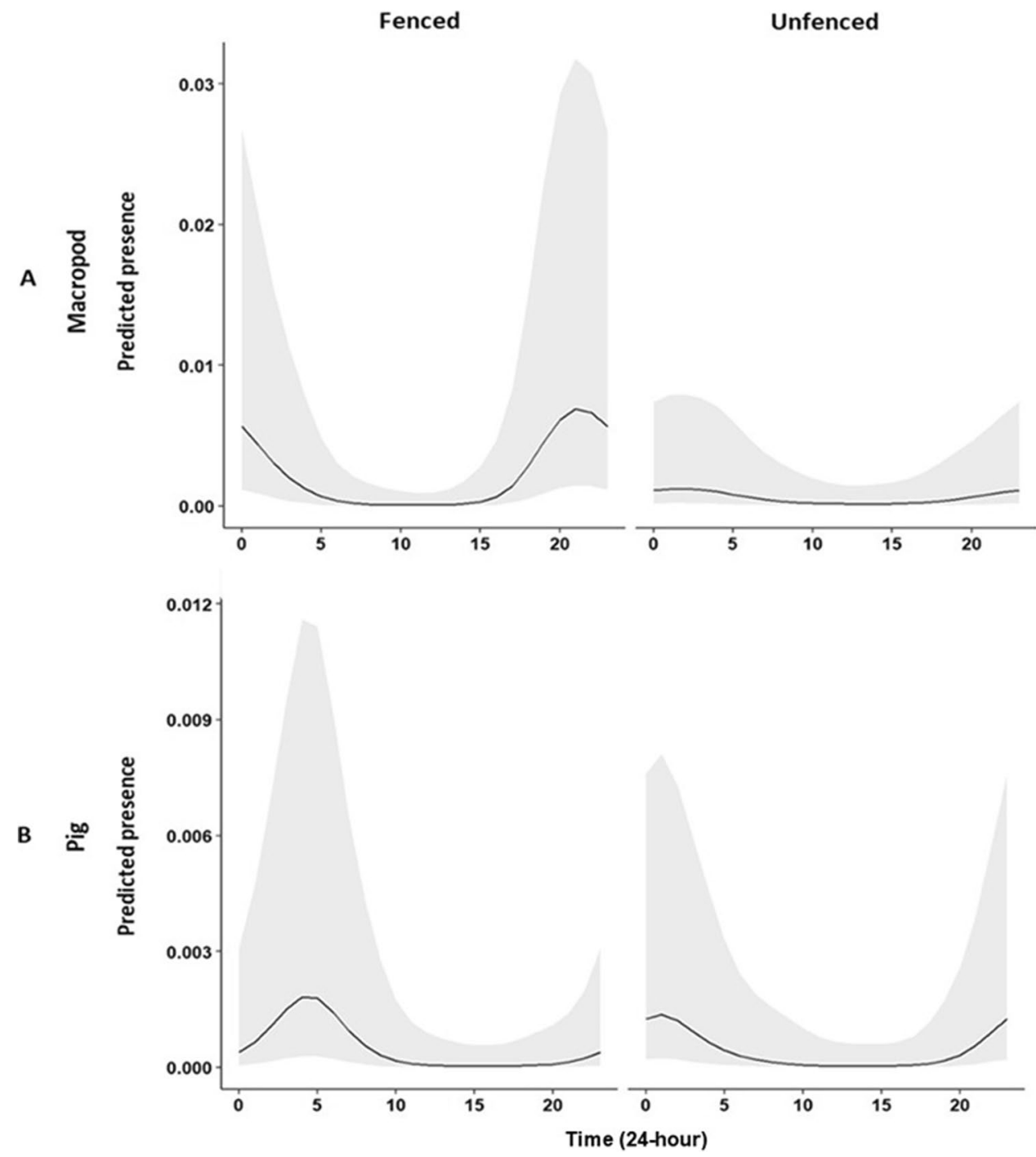

while the presence of macropods, pigs, cattle, and dingoes was not affected significantly (Table 2, Fig. 7).

\section{Discussion}

\section{Water scarcity and interspecific competition}

The presence of herbivores which are larger in size and/or behaviourally dominant can affect the visitation behaviour of competitively inferior species at waterholes (Ostermann-Kelm et al. 2008; Valeix et al. 2009; Hall et al. 2018). We assessed native macropod visitation to savanna waterholes and found they did not preferentially use sites where large feral ungulates were excluded, even when resources became scarce. We also found no significant difference in their overall temporal activity patterns (i.e., over the entire dry season) across the two fencing treatments. As our fencing experiment prevented buffalo and cattle from accessing fenced sites, we could not model their direct impact on the temporal behaviour of species which could access both fencing treatments (e.g., macropods) due to complete separation of the data. However, when we considered macropod behaviour during different stages of the dry season, we found that their temporal activity patterns differed significantly between fencing treatments during the middle of the dry season, when macropod presence at sites was greatest (but not at the start or end of the season). Compared to fenced sites, macropods visiting unfenced sites in the middle of the dry season had less defined activity patterns, and their peak activity occurred later at night. This may be explained by 
Table 4 GAMM results for influence of fencing treatment on predicted presence of macropods, pigs, and dingoes over different stages of the dry season (start, middle, and end). Models presented are the most favourable based on AIC values (see online supplementary material Table S2). Where $\Delta$ AIC $<2$, results for both models are presented

\begin{tabular}{|c|c|c|c|c|c|}
\hline Dry season stage & Species & Model terms & St. error & $z$ & $p$ \\
\hline \multirow[t]{6}{*}{ Start } & \multirow[t]{2}{*}{ Macropod } & Base model & 8179 & -0.002 & 0.998 \\
\hline & & $\begin{array}{l}\text { By factor for fencing treatment } \\
\text { included }\end{array}$ & - & - & - \\
\hline & \multirow[t]{2}{*}{ Pig } & Base model & 1.433 & -0.288 & 0.774 \\
\hline & & $\begin{array}{l}\text { By factor for fencing treatment } \\
\text { included }\end{array}$ & - & - & - \\
\hline & \multirow[t]{2}{*}{ Dingo } & Base model & 0.4427 & 0.144 & 0.885 \\
\hline & & $\begin{array}{l}\text { By factor for fencing treatment } \\
\text { included }\end{array}$ & - & - & - \\
\hline \multirow[t]{6}{*}{ Middle } & \multirow[t]{2}{*}{ Macropod } & Base model & 1.134 & -1.134 & 0.257 \\
\hline & & $\begin{array}{l}\text { By factor for fencing treatment } \\
\text { included }\end{array}$ & 1.241 & -0.453 & 0.6508 \\
\hline & \multirow[t]{2}{*}{ Pig } & Base model & 1.049 & -0.147 & 0.883 \\
\hline & & $\begin{array}{l}\text { By factor for fencing treatment } \\
\text { included }\end{array}$ & 1.307 & -0.032 & 0.9746 \\
\hline & \multirow[t]{2}{*}{ Dingo } & Base model & 0.4616 & 0.373 & 0.709 \\
\hline & & $\begin{array}{l}\text { By factor for fencing treatment } \\
\text { included }\end{array}$ & - & - & - \\
\hline \multirow[t]{6}{*}{ End } & \multirow[t]{2}{*}{ Macropod } & Base model & 1.593 & 0.139 & 0.890 \\
\hline & & $\begin{array}{l}\text { By factor for fencing treatment } \\
\text { included }\end{array}$ & - & - & - \\
\hline & \multirow[t]{2}{*}{ Pig } & Base model & 1.000 & 0.394 & 0.6939 \\
\hline & & $\begin{array}{l}\text { By factor for fencing treatment } \\
\text { included }\end{array}$ & - & - & - \\
\hline & \multirow[t]{2}{*}{ Dingo } & Base model & 0.6488 & 0.303 & 0.7622 \\
\hline & & $\begin{array}{l}\text { By factor for fencing treatment } \\
\text { included }\end{array}$ & - & - & - \\
\hline
\end{tabular}

Hyphens denote unfavourable models ( $\triangle \mathrm{AIC}>2$ ). See methods for a description of variables included in base models. See online supplementary material Fig. S1 for full dry season stage GAMM results for all species lower macropod attendance to unfenced sites during this stage, which may have confounded our results. In addition, the model which assumed macropods did not vary their temporal activity between fencing treatments was found to be the more favourable of the two supported models, and the temporal activity patterns of macropods did not differ across fencing treatments at the end of the dry season (when macropods visited unfenced sites most). However, as the model which assumed macropod temporal activity patterns did vary with fencing treatment during this stage was also supported, we cannot discount the possibility that competition from large ungulates may affect macropod behaviour. This may explain why macropod activity peaked at unfenced sites later at night, when cattle activity was lower. As resource scarcity can intensify interspecific competition and force species to adjust their temporal niche (Valeix et al. 2007; Hasui et al. 2009), our findings suggest that macropods may temporally avoid cattle as water scarcity increases. In addition, at the end of the dry season, macropod presence around waterholes declined rapidly in both years, while cattle presence continued to increase. Hence, when water scarcity peaks, macropods may not just temporally, but also spatially avoid waterholes in areas utilised by cattle due to interference competition, as has been demonstrated with feral horses (Equus caballus) (Ostermann-Kelm et al. 2008; Hall et al. 2018). While we acknowledge that not including direct interactions between heterospecifics in our modelling (due to zero inflation and complete separation of the data) may have lessened our ability to demonstrate clear impacts of ungulate presences on macropods, we believe that our fencing experiment and observed differences in temporal visitation patterns to waterholes provide insights into potential interference competition between native and introduced species for access to limited water resources.

Exploitative competition for food resources may also explain our results, as increasing cattle presence may have depleted green vegetation resources (e.g., riparian grasses, forbs, and sedges) which establish around waterhole peripheries as the dry season progresses. Macropods may be sensitive to this type of competition because they have narrower feeding niches than introduced ungulates (Reid et al. 2020). 

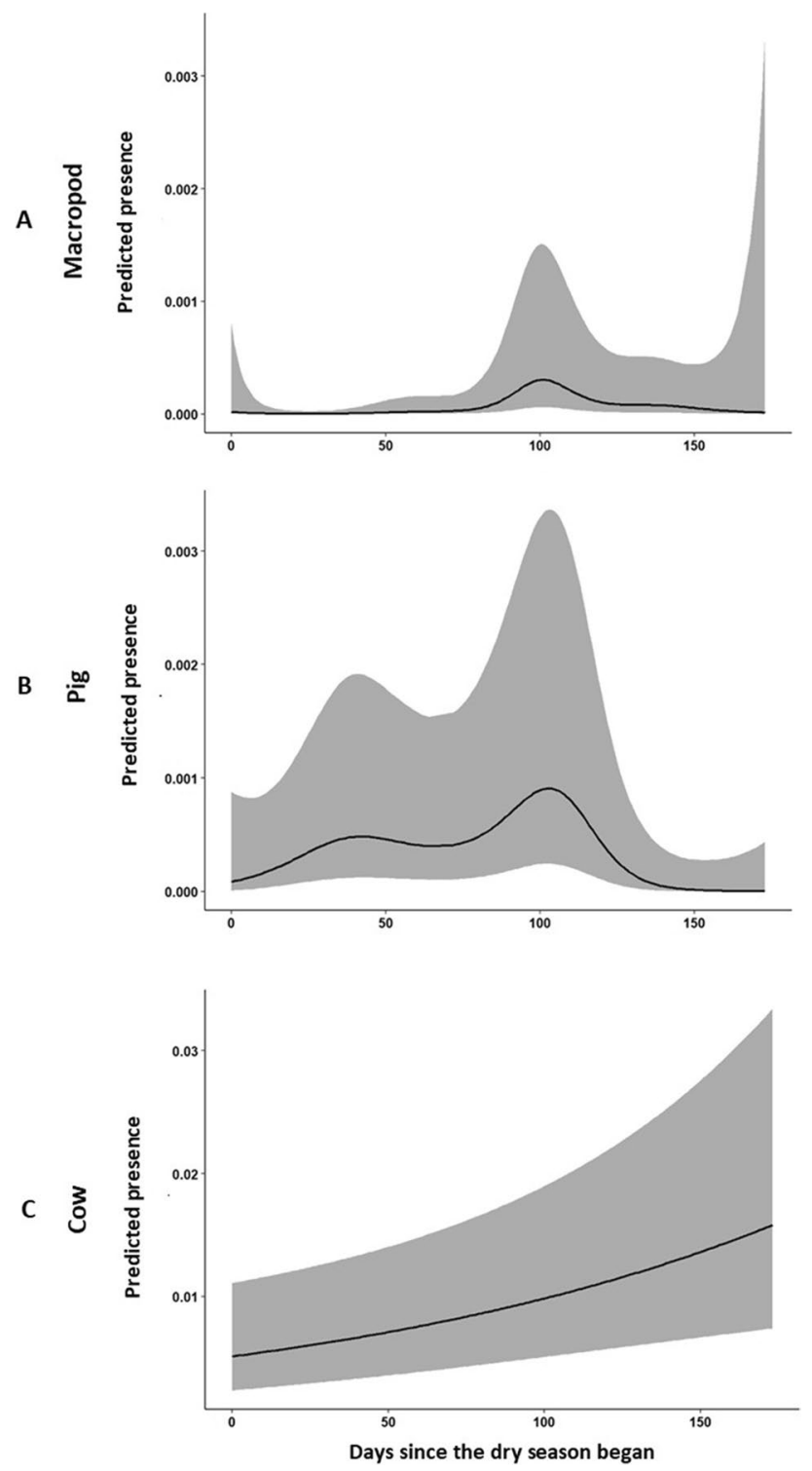

Fig. 5 Relationship between predicted hourly presence and days since the dry season began for macropods (a), pigs (b), and cattle (c) around waterholes in Limmen National Park. Mean presence values are shown as lines, while grey areas display upper and lower $95 \%$ confidence intervals

This is of concern because the competitive exclusion of native species by introduced competitors has potential fitness consequences, such as decreased growth and fecundity (Harris et al. 2006; Ayala et al. 2007). However, as macropod presence also declined rapidly at fenced waterholes at the end of the dry season, their response may be related to other seasonal factors not studied here (e.g., changes in food availability in the wider savanna, breeding cycles). Overall, our results suggest that small scale exclusion fencing may not affect macropod visitation to waterholes in areas where feral

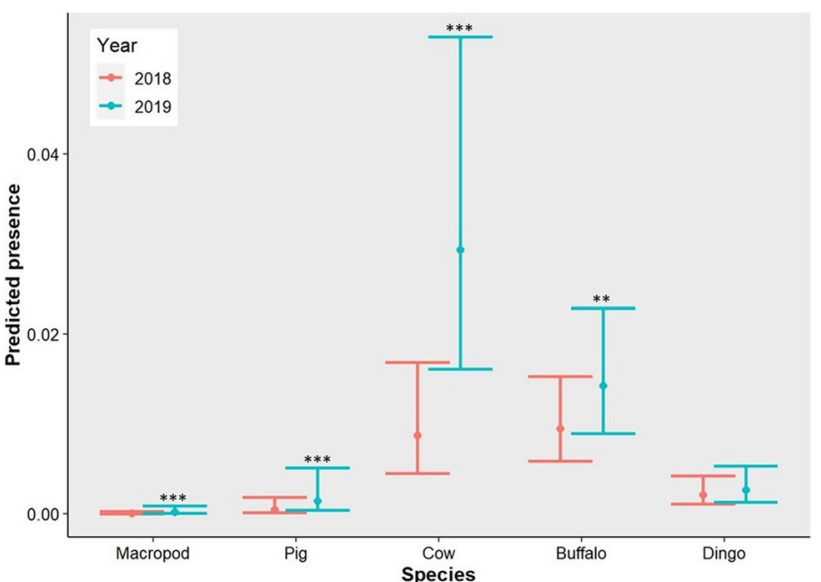

Fig. 6 Predicted hourly presence of macropods, ungulate species, and dingoes in 2018 and 2019 (drought). Points denote mean daily predicted presence values, while bars represent upper and lower 95\% confidence intervals. Significance levels: $* * *(p<0.001)$, ** $(p<0.01)$, none $(p>0.05)$

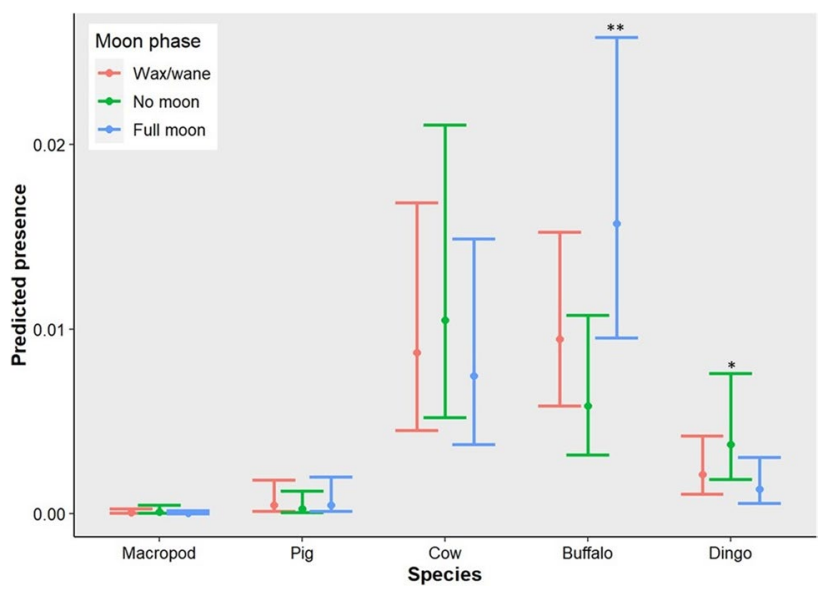

Fig. 7 Predicted hourly presence of macropods, ungulate species, and dingoes during different moon phases. Points denote mean daily predicted presence values, while bars represent upper and lower 95\% confidence intervals. Significance levels: $* *(p<0.01), *(p<0.05)$, none $(p>0.05)$

ungulates are present (at least not over short time spans), but more research is required.

In contrast to cattle, the presence of buffalo at study waterholes was not significantly affected by dry season progression. Buffalo have fewer sweat glands than other ungulates (e.g., cattle, sheep), forcing them to wallow regularly to thermoregulate (Tulloch and Litchfield 1981; Bracke 2011; Collier and Gebremedhin 2015). Hence, the progression of the dry season may have had little effect on their overall water requirements. We also found that the temporal activity patterns of pigs differed between fencing treatments during the middle of the dry season, with their activity peaking at unfenced sites several hours earlier than at fenced sites. This 
difference in pig behaviour could be explained by temporal avoidance of buffalo at unfenced sites, which are known interference competitors of pigs (Corbett 1995a; Finlayson et al. 1999). However, as with macropods, the model which assumed pig temporal activity did not vary between fencing treatments was the more favourable of the two supported models, and low pig visitation could have confounded our results. Pig activity also declined rapidly at the end of the dry season. However, as pigs forage on benthic vegetation (e.g., tubers of spike rushes and water lilies) at this time of year (Ridpath 1991), this response is likely due to declining food availability as study waterholes dried out, rather than competition.

Drought also affected animal visitation to savanna waterholes, resulting in significantly higher presences of macropods, pigs, and cattle. Buffalo presence also increased significantly during the drought, despite dry season progression having no effect on their behaviour. Ephemeral rainfall-fed water sources (such as the waterholes studied here) are sensitive to climatic variation and can dry faster in low rainfall years (Redfern 2002; Chamaillé-Jammes et al. 2007). Hence, the water demands of buffalo may have increased during the drought (but not necessarily over the dry season) due to reduced water availability across the landscape in that year. Our findings closely mirror those of a similar 2-year study in African savanna (Valeix 2011) and suggest that competition between feral ungulates and native wildlife for waterhole access may progressively intensify with increasing water scarcity. However, we acknowledge that the measures of water scarcity used here are coarse (i.e., days since the dry season began, year), and the availability of water at alternative waterpoints surrounding our study sites may have affected our results.

\section{Predator and prey responses to water scarcity and moon phase}

The threat of predation is not uniform in natural systems but varies both spatially and temporally due to changes in environmental conditions (Penteriani et al. 2013; Palmer et al. 2017). We found that both seasonal and interannual bottlenecks in water availability corresponded with increased prey presence (i.e., macropods, pigs, cattle, and buffalo) at savanna waterholes, similar to previous findings from Africa (Thrash et al. 1995). However, this did not correspond with increased dingo presence around waterholes, despite overlap in their temporal activity with all of the prey species studied. This could indicate that dingoes are not using waterholes as primary hunting grounds in this system, unlike in more arid parts of Australia (Shepherd 1981). Alternatively, dingoes may favour other prey during the dry season which are more prevalent in the surrounding savanna, such as reptiles, insects, and ground dwelling birds. Dingoes may also focus their hunting activity around larger, more permanent waterbodies than those studied here (e.g., large billabongs, wetlands) where prey visitation may be more consistent throughout the year. The drought could also have provided scavenging opportunities for dingoes away from waterpoints.

Predation threat can also vary with changes in night-time illumination (Harmsen et al. 2011; Penteriani et al. 2011, 2013; Palmer et al. 2017). We found that dingo activity around waterholes increased on moonless nights, suggesting that dingo hunting success may improve under low light conditions, as has been shown for other savanna predators (e.g., lions: Funston et al. 2001; Packer et al. 2011). This is because prey may find detection or defence against dingoes more difficult on moonless nights, particularly when young are present. In support of this theory, we observed two dingo predation attempts at waterholes during this study and both were targeted on ungulates with calves on moonless nights. Furthermore, while not significant, buffalo showed reduced activity on moonless nights compared to other moon phases. During the full moon, buffalo activity increased significantly compared to the wax/wane phase. However, as this did not correspond with a decline in dingo activity, the response of buffalo may not necessarily reflect changes in predation risk. Buffalo are primarily crepuscular; hence, they may utilise higher illumination levels during full moons for increased movement or foraging. In contrast, cattle are primarily diurnal, and pigs are most active during pre-dawn hours. Hence, moon phase may not provide them the same advantages and disadvantages as for buffalo, which may explain why no response to moon phase was observed in cattle and pigs.

Surprisingly, macropods did not shift their visitation behaviour in response to moon phase. However, macropod activity peaked during the night-time lull in dingo activity, which may be an antipredator response to limit their exposure to dingoes. Alternatively, macropods may increase their vigilance during moonless nights when predation risk is highest, rather than altering their overall visitation behaviour. Considering dingoes are the apex terrestrial predator in Australian ecosystems and have a reputation as a threat to livestock (Letnic et al. 2012), more studies which investigate how water scarcity and moon phase affect their hunting behaviour are needed.

Due to rising temperatures, climate change is predicted to increase evaporation in northern Australia (Dai et al. 2018; NESP Earth Systems and Climate Change Hub 2020), which will likely reduce surface water availability for savanna wildlife (Ritchie and Bolitho 2008). Advances in geospatial technologies may allow future studies to evaluate in detail how changing availability of water sources in savanna ecosystems drives the spatial-temporal distributions of both native wildlife and introduced ungulates. As pastoralism is a major land use in the region (Holmes 2010) and continuing to intensify due to recent 
improvements in remote cattle management technologies that allow increased stocking of remote areas (Hunt et al. 2013, 2014), competition between wildlife and ungulates (both feral and domestic) for access to water resources in Australian savannas is likely to intensify in the future. Our study highlights that feral ungulates may not only affect native wildlife communities indirectly (e.g., through changes to habitat structure and quality from vegetation grazing and tramping) but can also have direct impacts on the behaviour of native species. More research is needed to understand how the presence of introduced ungulates at water points impacts native wildlife communities in Australian savannas as availability of surface water sources may become more limited in space and time.

Supplementary Information The online version contains supplementary material available at https://doi.org/10.1007/s00265-022-03134-4.

Acknowledgements We thank the Parks and Wildlife Commission of the Northern Territory for their support of this study, as well as Wally Snelling and ranger James Vincent for their assistance installing and maintaining fences. The authors also thank Deanna Duffy from the Spatial Data Analysis Network (SPAN) at Charles Sturt University for assisting with the development of the map shown in Fig. 2. Finally, we thank the reviewers and editors for their helpful comments to improve the manuscript.

Author contribution All authors conceived and designed the study; HM conducted the field experiment and data collation; HM and DGN conducted the statistical analysis; all authors contributed to the writing and editing of the manuscript.

Funding Open Access funding enabled and organized by CAUL and its Member Institutions. This work was supported financially by the Hermon Slade Foundation (HSF 17/1), the Ecological Society of Australia (Holsworth Wildlife Research Endowment, 0000102503), Birdlife Australia (2017 Stuart Leslie Bird Research Award), and the Institute for Land, Water and Society (Charles Sturt University). HM was also funded by an Australian Government Research Training Program scholarship (Charles Sturt University).

Data availability All data analysed during this study are available in the supplementary material.

Code availability The modelling used for the statistical analysis is described in detail in the text, including the " $\mathrm{R}$ " packages used.

\section{Declarations}

Ethics approval Approval to conduct this study was granted by the Animal Care and Ethics Committee of Charles Sturt University (approved protocol number A17035) and the Parks and Wildlife Commission of the Northern Territory (permit number 61071). All field data collection adhered to the standards outlined in the Australian Code for the care and use of animals for scientific purposes and the Territory Parks and Wildlife Conservation Act 1976.

Consent for publication The authors consent to the publication of this manuscript in Behavioural Ecology and Sociobiology.
Conflict of interest The authors declare no competing interests.

Open Access This article is licensed under a Creative Commons Attribution 4.0 International License, which permits use, sharing, adaptation, distribution and reproduction in any medium or format, as long as you give appropriate credit to the original author(s) and the source, provide a link to the Creative Commons licence, and indicate if changes were made. The images or other third party material in this article are included in the article's Creative Commons licence, unless indicated otherwise in a credit line to the material. If material is not included in the article's Creative Commons licence and your intended use is not permitted by statutory regulation or exceeds the permitted use, you will need to obtain permission directly from the copyright holder. To view a copy of this licence, visit http://creativecommons.org/licenses/by/4.0/.

\section{References}

Akaike H (1973) Information theory and the maximum likelihood principle. In: Petrov B, Csaki F (eds) Second International Symposium on Information Theory, Budapest. Akademiai Kiado, Budapest, pp 199-213

Amarasekare P (2002) Interference competition and species coexistence. Proc R Soc Lond B 269:2541-2550

Ayala JR, Rader RB, Belk MC, Schaalje GB (2007) Ground-truthing the impact of invasive species: spatio-temporal overlap between native least chub and introduced western mosquitofish. Biol Invasions 9:857-869

Baskaran N, Ramkumaran K, Karthikeyan G (2016) Spatial and dietary overlap between blackbuck (Antilope cervicapra) and feral horse (Equus caballus) at Point Calimere Wildlife Sanctuary, Southern India: competition between native versus introduced species. Mamm Biol 81:295-302

Beaulieu M, Sockman KW (2012) One meadow for two sparrows: resource partitioning in a high elevation habitat. Oecologia 170:529-540

Bertolino S, Di Montezemolo NC, Preatoni DG, Wauters LA, Martinoli A (2014) A grey future for Europe: Sciurus carolinensis is replacing native red squirrels in Italy. Biol Invasions 16:53-62

Blossey B, Notzold R (1995) Evolution of increased competitive ability in invasive nonindigenous plants: a hypothesis. J Ecol 83:887-889

Bracke M (2011) Review of wallowing in pigs: description of the behaviour and its motivational basis. Appl Anim Behav Sci 132:1-13

Brim Box J, Bledsoe P, Box A et al (2019) The impact of camel visitation on native wildlife at remote waterholes in arid Australia. J Zool 309:84-93

Brook L, Kutt A (2011) The diet of the dingo (Canis lupus dingo) in north-eastern Australia with comments on its conservation implications. Rangeland J 33:79-85

Bureau of Meteorology (2021) Climate data online. CSIRO, http:// www.bom.gov.au/climate/data/index.shtml

Carothers JH, Jaksić FM (1984) Time as a niche difference: the role of interference competition. Oikos 42:403-406

Chamaillé-Jammes S, Fritz H, Murindagomo F (2007) Climate-driven fluctuations in surface-water availability and the buffering role of artificial pumping in an African savanna: potential implication for herbivore dynamics. Austral Ecol 32:740-748

Cheeseman AE, Ryan SJ, Whipps CM, Cohen JB (2018) Competition alters seasonal resource selection and promotes use of invasive shrubs by an imperiled native cottontail. Ecol Evol 8:11122-11133

Collier RJ, Gebremedhin KG (2015) Thermal biology of domestic animals. Annu Rev Anim Biosci 3:513-532 
Cook GD, Heerdegen RG (2001) Spatial variation in the duration of the rainy season in monsoonal Australia. Int J Climatol 21:1723-1732

Corbett L (1995a) Does dingo predation or buffalo competition regulate feral pig populations in the Australian wet-dry tropics? An experimental study. Wildlife Res 22:65-74

Corbett LK (1995b) The dingo in Australia and Asia. University of New South Wales Press, Sydney

Coulson G (1982) Road-kills of macropods on a section of highway in central Victoria. Wildlife Res 9:21-26

Cozzi G, Broekhuis F, McNutt JW, Turnbull LA, Macdonald DW, Schmid B (2012) Fear of the dark or dinner by moonlight? Reduced temporal partitioning among Africa's large carnivores. Ecology 93:2590-2599

Cunningham CX, Scoleri V, Johnson CN, Barmuta LA, Jones ME (2019) Temporal partitioning of activity: rising and falling toppredator abundance triggers community-wide shifts in diel activity. Ecography 42:2157-2168

Dai A, Zhao T, Chen J (2018) Climate change and drought: a precipitation and evaporation perspective. Curr Clim Chang Rep 4:301-312

Davidson Z, Valeix M, Van Kesteren F, Loveridge AJ, Hunt JE, Murindagomo F et al (2013) Seasonal diet and prey preference of the African Lion in a waterhole-driven semi-arid savanna. PLoS ONE 8(2):e55182. https://doi.org/10.1371/journal.pone.0055182

Ferry N (2018) Processes involved in the functioning of large mammal communities: the role of the African elephant in the ecology of predator-prey relationships. $\mathrm{PhD}$ thesis, Universite de Lyon

Finlayson C, Storrs M, Hall R, Bayliss B (1999) Management issues for northern Australian wetlands. In: Finlayson CM, Spiers AG (eds) A compendium of information for managing and monitoring wetlands in tropical Australia. Supervising Scientist Report 148. Supervising Scientist, Canberra, pp 143-167

Fleming P, Corbett L, Harden R, Thomson P (2001) Managing the impacts of dingoes and other wild dogs. Bureau of Rural Sciences, Canberra

Forsyth DM, Latham ADM, Davis NE, Caley P, Letnic M, Moloney PD, Woodford LP, Woolnough AP (2019) Interactions between dingoes and introduced wild ungulates: concepts, evidence and knowledge gaps. Aust Mammal 41:12-26

Frere E, Quintana F, Gandini P, Wilson RP (2008) Foraging behaviour and habitat partitioning of two sympatric cormorants in Patagonia, Argentina. Ibis 150:558-564

Funston P, Mills M, Biggs H (2001) Factors affecting the hunting success of male and female lions in the Kruger National Park. J Zool 253:419-431

Goodyear NC (1992) Spatial overlap and dietary selection of native rice rats and exotic black rats. J Mammal 73:186-200

Graz FP, Westbrooke ME, Florentine SK (2012) Modelling the effects of water-point closure and fencing removal: a GIS approach. J Environ Manage 104:186-194

Hall LK, Larsen RT, Westover MD, Day CC, Knight RN, McMillan BR (2016) Influence of exotic horses on the use of water by communities of native wildlife in a semi-arid environment. J Arid Environ 127:100-105

Hall LK, Larsen RT, Knight RN, McMillan BR (2018) Feral horses influence both spatial and temporal patterns of water use by native ungulates in a semi-arid environment. Ecosphere 9:e02096

Harmsen BJ, Foster RJ, Silver SC, Ostro LE, Doncaster C (2011) Jaguar and puma activity patterns in relation to their main prey. Mamm Biol 76:320-324

Harris DB, Gregory SD, Macdonald DW (2006) Space invaders? A search for patterns underlying the coexistence of alien black rats and Galapagos rice rats. Oecologia 149:276-288

Hasui É, Gomes VSdM, Kiefer MC, Tamashiro J, Silva WR (2009) Spatial and seasonal variation in niche partitioning between blue manakin (Chiroxiphia caudata) and greenish schiffornis
(Schiffornis virescens) in southeastern Brazil. Stud Neotrop Fauna E 44:149-159

Holmes J (2010) The multifunctional transition in Australia's tropical savannas: the emergence of consumption, protection and indigenous values. Geogr Res 48:265-280

Holway DA (1999) Competitive mechanisms underlying the displacement of native ants by the invasive Argentine ant. Ecology 80:238-251

Hunt L, McIvor J, Grice A, Bray S (2014) Principles and guidelines for managing cattle grazing in the grazing lands of northern Australia: stocking rates, pasture resting, prescribed fire, paddock size and water points-a review. Rangeland J 36:105-119

Hunt L, Petty S, Cowley R et al (2013) Sustainable development of Victoria River District (VRD) grazing lands. Meat \& Livestock Australia Limited, North Sydney, NSW

Kanniah KD, Beringer J, Hutley LB (2013) Response of savanna gross primary productivity to interannual variability in rainfall: results of a remote sensing based light use efficiency model. Prog Phys Geog 37:642-663

Latham J (1999) Interspecific interactions of ungulates in European forests: an overview. For Ecol Manage 120:13-21

Letnic M, Ritchie EG, Dickman CR (2012) Top predators as biodiversity regulators: the dingo Canis lupus dingo as a case study. Biol Rev 87:390-413

Linley G, Pauligk Y, Marneweck C, Ritchie E (2020) Moon phase and nocturnal activity of native Australian mammals. Aust Mammal 43:190-195

Linnell JD, Strand O (2000) Interference interactions, co-existence and conservation of mammalian carnivores. Divers Distrib 6:169-176

Lüdecke D (2018) ggeffects: tidy data frames of marginal effects from regression models. J Open Source Softw 3:772

Mihailou H, Massaro M (2021) An overview of the impacts of feral cattle, water buffalo and pigs on the savannas, wetlands and biota of northern Australia. Austral Ecol 46:699-712

Nakayama S, Fuiman LA (2010) Body size and vigilance mediate asymmetric interference competition for food in fish larvae. Behav Ecol 21:708-713

NESP Earth Systems and Climate Change Hub (2020) Climate change in the Northern Territory: state of the science and climate change impacts. NESP Earth Systems and Climate Change Hub, Melbourne

Newkirk ES (2016) CPW Photo Database, 4.3.0.5 edn. Colorado Parks and Wildlife, Fort Collins, CO, USA

Ostermann-Kelm S, Atwill ER, Rubin ES, Jorgensen MC, Boyce WM (2008) Interactions between feral horses and desert bighorn sheep at water. J Mammal 89:459-466

Packer C, Swanson A, Ikanda D, Kushnir H (2011) Fear of darkness, the full moon and the nocturnal ecology of African lions. PLoS ONE 6:e22285

Palmer M, Fieberg J, Swanson A, Kosmala M, Packer C (2017) A 'dynamic' landscape of fear: prey responses to spatiotemporal variations in predation risk across the lunar cycle. Ecol Lett 20:1364-1373

Penteriani V, Kuparinen A, del Mar DM, Lourenço R, Campioni L (2011) Individual status, foraging effort and need for conspicuousness shape behavioural responses of a predator to moon phases. Anim Behav 82:413-420

Penteriani V, Kuparinen A, del Mar DM et al (2013) Responses of a top and a meso predator and their prey to moon phases. Oecologia 173:753-766

Persson L (1985) Asymmetrical competition: are larger animals competitively superior? Am Nat 126:261-266

Peters RH, Peters RH (1986) The ecological implications of body size, vol 2. Cambridge University Press, Cambridge 
Petren K, Case TJ (1996) An experimental demonstration of exploitation competition in an ongoing invasion. Ecology 77:118-132

Pratas-Santiago LP, Gonçalves ALS, da Maia SA, Spironello WR (2016) The moon cycle effect on the activity patterns of ocelots and their prey. J Zool 299:275-283

R Core Team (2020) R: A language and environment for statistical computing. R Foundation for Statistical Computing, Vienna, Austria, http://www.R-project.org

Redfern JV (2002) Manipulating surface water availability to manage herbivore distributions in the Kruger National Park, South Africa. $\mathrm{PhD}$ thesis, University of California, Berkeley

Reid AM, Murphy BP, Vigilante T, Corporation WGA, Barry LA, Bowman DM (2020) Carbon isotope analysis shows introduced bovines have broader dietary range than the largest native herbivores in an Australian tropical savanna. Austral Ecol 45:109-121

Ridpath M (1991) Feral mammals and their environment. In: Haynes C, Ridpath M, Williams M (eds) Monsoonal Australia: landscape ecology and man in the northern lowlands. A.A. Balkema Publishers, Rotterdam, pp 169-191

Ritchie EG, Bolitho EE (2008) Australia's savanna herbivores: bioclimatic distributions and an assessment of the potential impact of regional climate change. Physiol Biochem Zool 81:880-890

Ritchie EG, Martin JK, Krockenberger AK, Garnett S, Johnson CN (2008) Large-herbivore distribution and abundance: intraand interspecific niche variation in the tropics. Ecol Monogr 78:105-122

Shepherd N (1981) Predation of Red Kangaroos, Macropus rufus, by the Dingo, Canis familiaris dingo (Blumenbach) in North-Western New South Wales. Wildlife Res 8:255-262

Skeat AJ, East J, Corbett LK (1996) Impact of feral water buffalo. In: Finlayson CM, von Oertzen I (eds) Landscape and vegetation ecology of the Kakadu region, Northern Australia. Kluwer Academic Publishers, Amsterdam, pp 155-177

Staniewicz A, Behler N, Dharmasyah S, Jones G (2018) Niche partitioning between juvenile sympatric crocodilians in Mesangat Lake, East Kalimantan, Indonesia. Raffles Bull Zool 66:528-537

Taylor JA, Tulloch DON (1985) Rainfall in the wet-dry tropics: extreme events at Darwin and similarities between years during the period 1870-1983 inclusive. Austral Ecol 10:281-295

Thomson P (1992) The behavioural ecology of dingoes in northwestern Australia. III. Hunting and feeding behaviour, and diet. Wildlife Res 19:531-541

Thrash I, Theron G, Bothma JdP (1995) Dry season herbivore densities around drinking troughs in the Kruger National Park. J Arid Environ 29:213-219
Tomkins N, O'Reagain P (2007) Global positioning systems indicate landscape preferences of cattle in the subtropical savannas. Rangeland J 29:217-222

Tulloch D, Litchfield R (1981) Wallows for buffalo. Wildlife Res $8: 555-565$

Vahl WK, van der Meer J, Weissing FJ, van Dullemen D, Piersma T (2005) The mechanisms of interference competition: two experiments on foraging waders. Behav Ecol 16:845-855

Valeix M (2011) Temporal dynamics of dry-season water-hole use by large African herbivores in two years of contrasting rainfall in Hwange National Park, Zimbabwe. J Trop Ecol 27:163-170

Valeix M, Chamaillé-Jammes S, Fritz H (2007) Interference competition and temporal niche shifts: elephants and herbivore communities at waterholes. Oecologia 153:739-748

Valeix M, Fritz H, Matsika R, Matsvimbo F, Madzikanda H (2008) The role of water abundance, thermoregulation, perceived predation risk and interference competition in water access by African herbivores. Afr J Ecol 46:402-410

Valeix M, Fritz H, Canévet V, Le Bel S, Madzikanda H (2009) Do elephants prevent other African herbivores from using waterholes in the dry season? Biodivers Conserv 18:569-576

Valeix M, Loveridge AJ, Davidson Z, Madzikanda H, Fritz H, Macdonald DW (2010) How key habitat features influence large terrestrial carnivore movements: waterholes and African lions in a semi-arid savanna of north-western Zimbabwe. Landscape Ecol 25:337-351

Wauters LA, Gurnell J, Martinoli A, Tosi G (2002) Interspecific competition between native Eurasian red squirrels and alien grey squirrels: does resource partitioning occur? Behav Ecol Sociobiol 52:332-341

Wickham H (2016) ggplot2: elegant graphics for data analysis. Springer-Verlag, New York

Wood SN (2006) Generalized additive models: an introduction with R. CRC Press, Boca Raton

Wood S, Scheipl F (2020) gamm4: Generalized Additive Mixed Models using 'mgcv' and 'lme4', R package version 0.2-6, https:// cran.r-project.org/web/packages/gamm4/gamm4.pdf

Ziv Y, Abramsky Z, Kotler BP, Subach A (1993) Interference competition and temporal and habitat partitioning in two gerbil species. Oikos 66:237-246

Zuur A, Ieno EN, Walker N, Saveliev AA, Smith GM (2009) Mixed effects models and extensions in ecology with R. Springer Science \& Business Media, Berlin

Publisher's note Springer Nature remains neutral with regard to jurisdictional claims in published maps and institutional affiliations. 